Research Paper

\title{
Efficacy of Continuous Care Model Implementation on Body Mass Index and Lifestyle of Middle-aged Obese People
}

\author{
Mitra Tavakolizadeh $^{1}$ (D), Mahdi Moshki² (D, Mahdi Basiri Moghadam³ (D, Ali Delshad ${ }^{4^{*}}$ (D) \\ 1. Clinical Research Development Unit, Bohlool Hospital, Gonabad University of Medical Sciences, Gonabad, Iran. \\ 2. Department of Health Education and Health Promotion, School of Health, Gonabad University of Medical Sciences, Gonabad, Iran. \\ 3. Department of Pediatric Nursing, Social Development and Health Promotion Research Center, School of Nursing, Gonabad University of Medical \\ Sciences, Gonabad, Iran. \\ 4. Department of Community Health Nursing \& Nursing Management, Social Development and Health Promotion Research Center, School of Nursing, \\ Gonabad University of Medical Sciences, Gonabad, Iran
}

\begin{tabular}{|c|c|}
\hline $\begin{array}{l}\text { Use your device to scan } \\
\text { and read the article online }\end{array}$ & Ctration Tavakolizadeh M, Moshki M, Basiri Moghadam M, Delshad A. Efficacy of Continuous Care Model Implementation \\
\hline 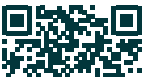 & $\begin{array}{l}\text { on Body Mass Index and Lifestyle of Middle-aged Obese People. Journal of Research \& Health. 2021; 11(6):413-422. http:// } \\
\text { dx.doi.org/\%2010.32598/JRH.11.6.1901.1 }\end{array}$ \\
\hline 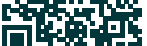 & dol http://dx.doi.org/\%2010.32598/JRH.11.6.1901.1 \\
\hline
\end{tabular}

\section{(i) \$}

Article info:

Received: 12 May 2021

Accepted: 14 Aug 2021

Publish: 01 Dec 2021

\section{A B S T RACT}

Background: This study aimed to determine the effect of continuous care model application on body mass index and lifestyle of middle-aged obese people.

Methods: A total of 105 obese middle-aged people were selected and randomly assigned to two groups. The study data were collected using a meter, scale, and the Walker Health Promotion Lifestyle questionnaire (HPLP II). The participants completed the questionnaire before and one, two, and three months after the intervention

Results: There was no significant difference between the experimental and control groups before the intervention considering all studied variables. However, a significant difference was observed between groups after the intervention regarding lifestyle dimensions and obesity control performance.

Conclusion: Our study showed that the continuous care model could effectively improve the lifestyle and health of middle-aged obese people. Therefore, this model is recommended as a framework to design an overweight and obesity prevention plan.

\footnotetext{
* Corresponding Author:

Ali Delshad, PhD.

Address: Department of Community Health Nursing \& Nursing Management, Social Development and Health Promotion Research Center, School of Nursing, Gonabad University of Medical Sciences, Gonabad, Iran.

Phone: +98 (915) 1778795

E-mail: alidelshad2000@yahoo.com
} 


\section{Introduction}

besity and overweight are undesirable $\mathbf{0}$ in society [1]. The extent of overweight and obesity effects on health depends on their degree and the distribution of fat in the body [2]. The World Health Organization (WHO) has classified Body Mass Index (BMI) ranges of $20-25,25-30$, and $>30 \mathrm{~kg} / \mathrm{m}^{2}$ as normal, overweight, and obese, respectively. Because of the prevalence of obesity in Iran and the world, focusing on this issue seems necessary [3]. According to WHO, 1.6 billion adults worldwide suffer from overweight, and the prevalence of overweight and obesity in Iran is $32 \%$ and $18.1 \%$, respectively [4]. Obesity is associated with increased risk of lipid profile, blood pressure, atherosclerosis, type II diabetes mellitus, arthritis, depression, and breast and colon cancers [5-7]. In addition, a high correlation is observed between BMI and cardiovascular disorders $[8,9]$. Also, a relationship has been reported between obesity and behavioral risk factors, as well as demographic and socioeconomic characteristics, such as dietary habits, gender, educational level, lactation to children, age, and history of obesity [10].

A lot of research has been done on obesity treatment methods. The main goal of the treatment is weight loss. The main benefit of weight loss is to correct or prevent cardiovascular risk factors [11]. The development of society requires active and healthy people. The issue of health depends on many factors such as lifestyle [12] that includes behaviors, such as eating habits, sleep and rest, physical activity and exercise, weight control, smoking and alcohol consumption, immunization against disease, adaptation to stress, and the ability to use family and community $[13,14]$. People strive to choose a lifestyle to maintain their health and prevent illness.

Non-communicable diseases, especially obesity, have a close relationship with lifestyle. In other words, lifestyle is one of the important determinants of individual health [15]. Health promotion behavior is considered a significant factor in the health promotion concept and healthcare [16]. To change unsafe behaviors and promote health, nurses resort to interventions and various models as a performance guide. One of these models is the continuous care model, which is a systematic and continuous process to create an effective, intermittent, and consistent communication between the patient as a care taker and the nurse as the health care provider. This model aims to recognize the needs and problems, sensitize patients to accept and conduct ongoing health behaviors, maintain recovery and promote patients' health. In Iran, Ahmadi in 2001 prepared a continuous care model concerning chronic coronary patients. This model has four stages: identification, sensitization, control, and evaluation. In Ahmadi's model, the patient is considered a continuing and effective care case in the health process [17].

Various studies have reported numerous positive effects of this model. For example, it improved the quality of life of schizophrenic [18] and hemodialysis patients [19] and decreased the re-admission and chest pain of patients with coronary artery disease [17]. The main goal of the continuous care model is developing programs that can result in the adoption and enhancement of insight and adequate performance to control the disease and its complications. The basic functions of this model include recognizing the illness and its nature, recognizing the actual and potential problems induced by the disease, accepting the disease and its effects on life, implementing the role of continuous self-control (good health behaviors), investing in maintaining and valuing health, engaging family for the management of current and immediate problems, changing the patterns and lifestyles, enhancing self-esteem, recognizing the care and treatment team and benefiting from them [20, 21]. The continuous care model establishes and maintains a dynamic, flexible, and continuous communication between the nurse and the patient to improve the patients' lifestyle [22].

With respect to the high prevalence of obesity and its adverse effects on the body, especially during middle age, nurses should identify and provide strategies for improving and promoting obese people's health and reducing obesity, and promoting their lifestyles based on some patterns. Therefore, this study aimed to determine the effect of the continuous care model on Body Mass Index (BMI) and lifestyle of obese middle-aged people at Gonabad University of Medical Sciences.

\section{Methods}

The present randomized clinical trial with a pretestpost-test design was performed on 105 obese middleaged people referred to Gonabad healthcare centers during 2014-2015. The current study was approved by the Ethics Committee of Gonabad University of Medical Sciences (gmu.irec.1393.89) and was recorded in IRCT (Code: 2016070428790N1).

The sample size was estimated using the following formula (comparing the average of two independent communities) with a confidence interval of $99 \%$ and power of $80 \%$. The basic parameters are inserted in the formula 
based on the Ghavami et al. study [17], and 48 people were determined for each group, which increased to 53 people considering a $10 \%$ dropout.

Also, one person from the control group was excluded from the study due to unwillingness to continue cooperation (Figure 1).

$$
n=\frac{\left(z_{1-\frac{a}{2}}+z_{1-\beta}\right)^{2}\left(s_{2}^{1}+s_{2}^{2}\right)}{\left.\mu_{1}-\mu_{2}\right)^{2}}=\frac{11.70\left(172.59^{2}+142.45^{2}\right)}{\left(45.97^{2}+42.35^{2}\right)} \cong 48
$$

To determine the BMI, we used the following Equation:

\section{$B M I=$ Weight $(\mathrm{kg}) /$ Height $^{2}\left(\mathrm{~m}^{2}\right)$}

Standard scales were used to measure participants' height and weight.

\section{Study instrument}

The study questionnaire consisted of three sections: demographic characteristics, Walker Health Promotion Lifestyle dimensions (HPLP II), and obesity control performance. The HPLP II questionnaire is an appropriate localized tool for measuring health-promoting behaviors. It has 52 questions in 6 subscales (nutrition, physical activity, health responsibility, stress management, interpersonal relationships, and spiritual growth). The validity and reliability of the Persian version of this questionnaire were examined by Mohammadi Zeidi et al., who reported the Cronbach $\alpha$ coefficients for the whole scale as 0.82 and the subcategories from 0.44 to 0.91 [19]. The questions are scored on a 4-point Likert scale (never, sometimes, often, and routinely). The minimum and maximum total scores are 52 and 208, respectively.

Also, a researcher-made questionnaire was designed to determine the performance of obesity control, to unravel one's performance toward observing the necessary principles for controlling obesity, and to assess the impact of continuous care model implementation. This questionnaire consisted of 40 questions in 4 dimensions: diagnosis and follow-up, correct nutrition, correct habits, and proper physical activity. It is ranked on a performance scale of Yes (1) and No (0). The total score of the questionnaire was obtained from sum of its subscales scores. The content validity of the questionnaire was obtained by preparing the questionnaire based on the continuous care model and considering reliable scientific sources. Then, the questionnaire was handed to 10 professors with sufficient expertise and experience. Finally, the questionnaire was revised with respect to their comments, and its validity was approved.
The reliability of the questionnaire was evaluated using the Coder-Richardson method. The internal consistency of the whole questionnaire was 0.78 , of diagnosis and follow-up dimension 0.84 , of proper nutrition 0.73 , of correct habits 0.80 , and of appropriate physical activity 0.75 .

At first, the participants were selected among the individuals referred to Gonabad City healthcare centers, Iran using a convenience sampling method. Also, they must meet the following criteria: aged 41-60 years, with BMI higher than 30, not under a specific diet, no liver disease, kidney failure, high blood pressure, diabetes, and depression, not using lipid-lowering drugs during the previous 3 months, being literate, and able to take care of themselves. After obtaining their written consent, the participants entered the study. They were randomly assigned to two groups of control and experimental using the permuted-block randomization method.

The control group received routine care that contained oral training by a health center expert. However, the experimental group underwent a weight control program based on the continuous care model depicted in the following four steps:

Identification: The goal of this step is to identify the patient and the nurse and to explain all the steps of the model. This step consists of the introduction of the nurse to the patient, clarifying nurses' expectations at all stages of the study, identifying the patients' expectations, determining the preferred method of communication (face to face or phone calls), agreeing on appointment times, and clarifying the goals of the study. The identification step lasted for half an hour or one hour for each participant, during which BMI, lifestyle, and obesity control performance were preliminary reviewed.

Sensitization: This step involved examining the participant's status, clarifying the participant's educational needs, explaining obesity, obesity-induced complications (the present and possible ones), the necessity of considering obesity control regimes, studying basic needs concerning diet and physical activities, elucidating problems caused by lack of attention to weight control, illustrating weight loss patterns, the importance of care continuity behaviors in maintaining health and controlling its complications, addressing the intended questions and answers with emphasis on risk factors to help the patient understand the nature of obesity and its early and late complications and to involve the patient with obesity-induced complications. Depending on the participants' tolerance, comprehension, awareness, knowledge, and problems, 4 to 6 sessions were held, which 


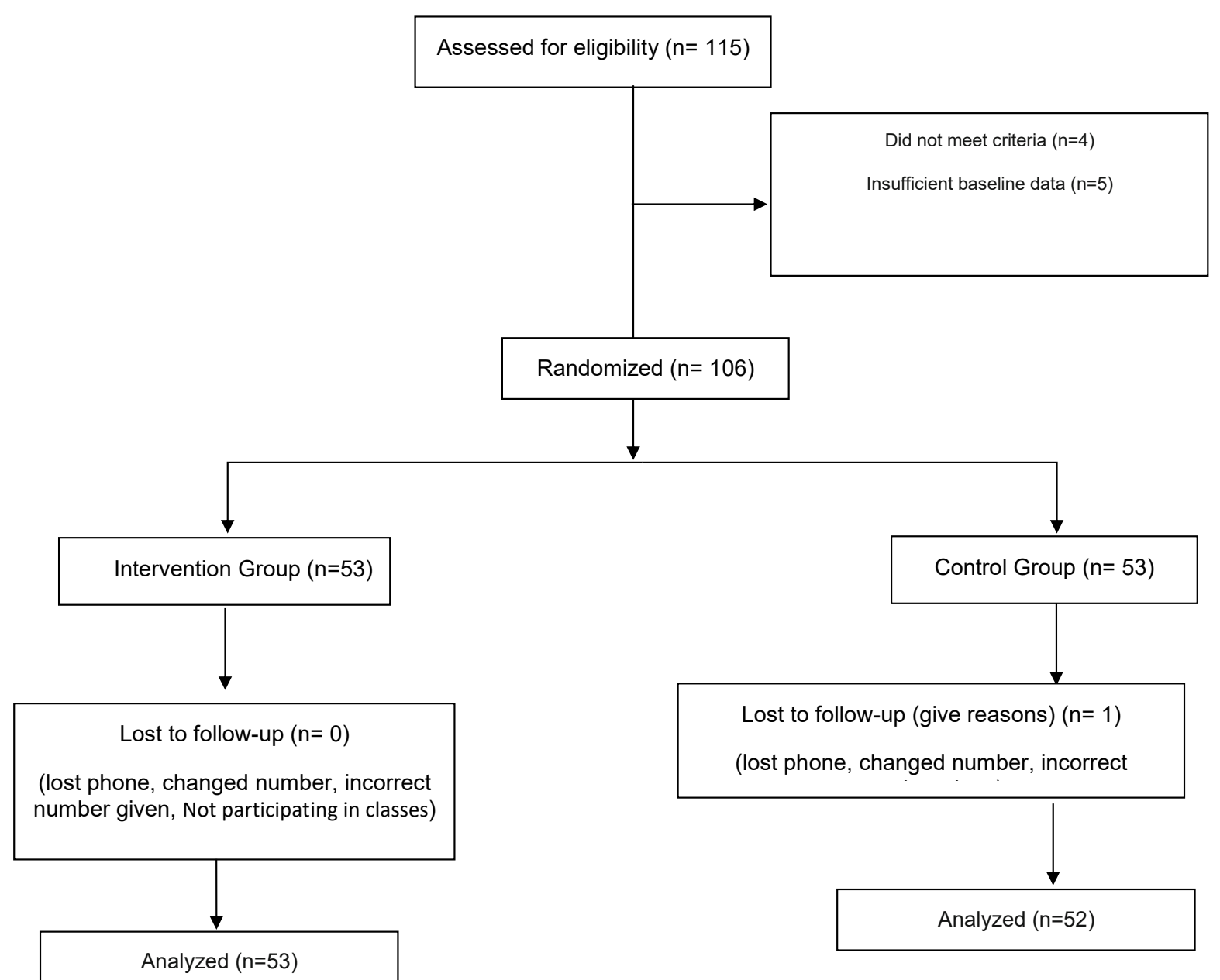

Figure 1. Consort of study design

mRA

lasted 1 to 2 hours in groups of 5 to 7 . In addition, individual sessions were held to complete the discussions and help participants who were not present at the training sessions. The identification and sensitization steps were held during the first 3 weeks of each month, for 3 consecutive months.

Control: The goal of this stage was to institutionalize and sustain health-promoting behaviors by resorting to practices, such as weight control regimens, indirect evaluation of acquired skills, the sustainability of health behaviors examination, consideration of new needs with regard to new problems, and re-sensitization to solve the problems, health behaviors reinforcement and justification of intervention beneficial effects, signifying concrete indicator improvements, controlling the studied indicators, explaining the proposed solution by the participant, enhancing personal and telephone communications, gaining participants' trust, institutionalizing the continuity of behaviors, and controlling, removing, or adjusting obesity risk factor. At this stage, continuous care consultations were performed weekly through face-to-face talking or phone calls tailored to the care needs of the experimental group. At the end of each month, BMI, lifestyle, and obesity control performance were evaluated in both groups.

Evaluation: Although the evaluation was the fourth and final step of the model, the BMI, lifestyle, and obesity control performance were evaluated in both groups at all stages. It should be noted that no intervention was done in the control group. The participants completed the questionnaires in the experimental and control groups before and one, two, and three months after the intervention.

The statistical analyses were performed at a $95 \%$ confidence level using the SPSS v. 20 software. The relationships between the dependent and independent variables were investigated using the paired and independent $t$ tests, repeated measures Analysis of Variance (ANOVA) for continuous variables, and the Chi-square test for categorical variables. 
Table 1. Demographic characteristics of the study participants

\begin{tabular}{|c|c|c|c|c|c|}
\hline \multirow{2}{*}{\multicolumn{2}{|c|}{ Variables }} & \multicolumn{2}{|c|}{ No. (\%) } & \multirow{2}{*}{$\mathbf{P}$} & \multirow{2}{*}{ Statistical Test } \\
\hline & & Case Group & Control Group & & \\
\hline \multirow{3}{*}{ Gender } & Female & $29(54.70)$ & $28(53.80)$ & \multirow{3}{*}{0.93} & \multirow{3}{*}{$\chi^{2}$} \\
\hline & & & & & \\
\hline & Male & $24(45.30)$ & $24(46.20)$ & & \\
\hline \multirow{5}{*}{ Marital status } & Married & $48(90.60)$ & $46(88.50)$ & \multirow{5}{*}{0.68} & \multirow{5}{*}{$\chi^{2}$} \\
\hline & Single & $0(0)$ & $1(1.90)$ & & \\
\hline & & & & & \\
\hline & Death spouse & $1(1.90)$ & $2(3.80)$ & & \\
\hline & Divorced & $4(7.50)$ & $3(5.80)$ & & \\
\hline \multirow{5}{*}{ Education level } & Illiterate & $24(45.30)$ & $24(46.20)$ & \multirow{5}{*}{0.96} & \multirow{5}{*}{ - } \\
\hline & Primary & $13(24.50)$ & $14(26.90)$ & & \\
\hline & & & & & \\
\hline & High school & $8(15.10)$ & $8(15.40)$ & & \\
\hline & Diploma & $8(15.10)$ & $6(11.50)$ & & \\
\hline \multirow{5}{*}{ Employment } & Unemployed & $3(5.70)$ & $4(7.70)$ & \multirow{5}{*}{0.93} & \multirow{5}{*}{ - } \\
\hline & Employed & $5(9.40)$ & $7(13.50)$ & & \\
\hline & Self-employed & $6(11.30)$ & $7(13.50)$ & & \\
\hline & Housewife & $15(28.30)$ & $13(25.0)$ & & \\
\hline & Retired & $21(40.40)$ & $24(45.30)$ & & \\
\hline \multirow{3}{*}{ Smoking } & Yes & $16(30.20)$ & $14(0.26)$ & \multirow{3}{*}{0.88} & \multirow{3}{*}{-} \\
\hline & & & & & \\
\hline & No & $37(69.80)$ & $38(0.73)$ & & \\
\hline
\end{tabular}

UPA

\section{Results}

The current investigation was conducted on 105 participants. The Mean \pm SD age of the participants in the experimental group was $48.7 \pm 5.37$ years, and in the control group was $48.55 \pm 5.59$ years. The two groups were homogenous in gender, marital status, education level, employment status, income, and smoking (Table 1).

The results of repeated measures ANOVA indicated no significant difference between the two groups regarding BMI $(\mathrm{P}=0.49, \mathrm{~F}=0.055)$ (Table 2).

Table 2. Comparing Mean \pm SD of BMI in different stages of study between the two groups using independent $t$-test

\begin{tabular}{|c|c|c|c|c|}
\hline \multirow{2}{*}{ Stages } & \multicolumn{2}{|c|}{$\mathrm{BMI}, \mathrm{Kg} / \mathrm{m}^{2}$ (Mean $\left.\pm S D\right)$} & \multicolumn{2}{|c|}{ Statistical Test } \\
\hline & Case Group & Control Group & $\mathbf{P}$ & $\mathbf{t}$ \\
\hline Before the intervention & $35.97 \pm 2.99$ & $35.86 \pm 3.23$ & 0.84 & 0.19 \\
\hline One month after the intervention & $35.80 \pm 2.98$ & $35.87 \pm 3.22$ & 0.91 & 0.11 \\
\hline Two months after the intervention & $35.73 \pm 3.07$ & $35.83 \pm 3.26$ & 0.87 & 0.17 \\
\hline Three months after the intervention & $35.68 \pm 3.02$ & $35.80 \pm 3.24$ & 0.84 & 0.20 \\
\hline
\end{tabular}


Table 3. Comparing Mean \pm SD scores of health-promoting lifestyle dimensions in different stages of study between the two groups

\begin{tabular}{|c|c|c|c|c|}
\hline \multirow{2}{*}{ Lifestyle Dimensions } & \multirow{2}{*}{ Stages } & \multicolumn{2}{|c|}{ Mean $\pm S D$} & \multirow{2}{*}{$\mathbf{P}$} \\
\hline & & Case & Control & \\
\hline \multirow{4}{*}{ Spiritual growth } & Before the intervention & $17.11 \pm 4.10$ & $18.08 \pm 3.58$ & 0.20 \\
\hline & One month after the intervention & $17.70 \pm 4.39$ & $18.56 \pm 3.77$ & 0.28 \\
\hline & Two months after the intervention & $18.11 \pm 4.37$ & $18.94 \pm 3.83$ & 0.30 \\
\hline & Three months after the intervention & $18.62 \pm 4.27$ & $19.04 \pm 3.72$ & 0.76 \\
\hline \multirow{4}{*}{ Health Responsibility } & Before the intervention & $17.21 \pm 3.63$ & $17.46 \pm 4.15$ & 0.74 \\
\hline & One month after the intervention & $18.09 \pm 3.42$ & $18.40 \pm 4.19$ & 0.68 \\
\hline & Two months after the intervention & $18.62 \pm 3.48$ & $18.85 \pm 3.86$ & 0.76 \\
\hline & Three months after the intervention & $19.17 \pm 3.56$ & $19.08 \pm 3.59$ & 0.89 \\
\hline \multirow{4}{*}{ Interpersonal Relations } & Before the intervention & $18.66 \pm 3.98$ & $17.63 \pm 4.19$ & 0.20 \\
\hline & One month after the intervention & $19.34 \pm 4.24$ & $18.13 \pm 4.08$ & 0.14 \\
\hline & Two months after the intervention & $19.87 \pm 4.12$ & $18.31 \pm 3.09$ & 0.05 \\
\hline & Three months after the intervention & $20.49 \pm 3.83$ & $18.96 \pm 3.66$ & 0.04 \\
\hline \multirow{5}{*}{ Stress management } & Before the intervention & $18.75 \pm 3.99$ & $18.15 \pm 4.10$ & 0.45 \\
\hline & One month after the intervention & $20.60 \pm 4.64$ & $18.90 \pm 4.02$ & 0.04 \\
\hline & & & & \\
\hline & Two months after the intervention & $21.02 \pm 4.56$ & $19.33 \pm 3.94$ & 0.04 \\
\hline & Three months after the intervention & $21.47 \pm 4.16$ & $19.65 \pm 3.77$ & 0.02 \\
\hline \multirow{4}{*}{ Physical Activity } & Before the intervention & $17.47 \pm 4.24$ & $18.21 \pm 4.41$ & 0.38 \\
\hline & One month after the intervention & $21.02 \pm 4.00$ & $19.06 \pm 3.98$ & 0.01 \\
\hline & Two months after the intervention & $22.47 \pm 3.72$ & $19.13 \pm 3.97$ & $<0.001$ \\
\hline & Three months after the intervention & $23.34 \pm 2.89$ & $19.42 \pm 3.91$ & $<0.001$ \\
\hline \multirow{4}{*}{ Nutrition } & Before the intervention & $15.53 \pm 3.41$ & $15.75 \pm 3.75$ & 0.75 \\
\hline & One month after the intervention & $19.79 \pm 3.71$ & $16.40 \pm 4.23$ & $<0.001$ \\
\hline & Two months after the intervention & $20.92 \pm 3.63$ & $16.65 \pm 4.33$ & $<0.001$ \\
\hline & Three months after the intervention & $22.34 \pm 3.65$ & $17.12 \pm 4.16$ & $<0.001$ \\
\hline \multirow{5}{*}{ Total } & Before the intervention & $104.74 \pm 9.60$ & $105.29 \pm 10.60$ & 0.78 \\
\hline & One month after the intervention & $116.55 \pm 10.60$ & $109.46 \pm 11.25$ & 0.001 \\
\hline & & & & \\
\hline & Two months after the intervention & $121.02 \pm 10.57$ & $111.21 \pm 10.78$ & 0.001 \\
\hline & Three months after the intervention & $125.43 \pm 10.34$ & $113.27 \pm 9.47$ & 0.001 \\
\hline
\end{tabular}


Table 4. Comparing Mean \pm SD dimensions of obesity control performance in different stages of study between the two groups

\begin{tabular}{|c|c|c|c|c|c|}
\hline \multirow{2}{*}{$\begin{array}{l}\text { Aspect Control Func- } \\
\text { tion Obesity }\end{array}$} & \multirow{2}{*}{ Stages } & \multicolumn{2}{|c|}{ Mean $\pm S D$} & \multirow{2}{*}{$\mathbf{P}$} & \multirow{2}{*}{ Test } \\
\hline & & Case & Control & & \\
\hline \multirow{4}{*}{ Detection and follow-up } & Before the intervention & $2.34 \pm 0.99$ & $2.27 \pm 1.06$ & 0.78 & \multirow{4}{*}{$\begin{array}{l}\text { The Mann- } \\
\text { Whitney }\end{array}$} \\
\hline & One month after the intervention & $2.64 \pm 1.02$ & $2.38 \pm 0.95$ & 0.24 & \\
\hline & Two months after the intervention & $2.92 \pm 1.01$ & $2.37 \pm 1.01$ & 0.75 & \\
\hline & Three months after the intervention & $3.11 \pm 1.05$ & $2.38 \pm 0.93$ & $<0.001$ & \\
\hline \multirow{4}{*}{ Nutrition } & Before the intervention & $17.08 \pm 3.80$ & $16.75 \pm 3.99$ & 0.67 & \multirow{4}{*}{$\begin{array}{l}\text { Indepen- } \\
\text { dent t-test }\end{array}$} \\
\hline & One month after the intervention & $18.45 \pm 2.99$ & $17.08 \pm 3.53$ & 0.03 & \\
\hline & Two months after the intervention & $18.09 \pm 3.60$ & $16.96 \pm 3.66$ & 0.11 & \\
\hline & Three months after the intervention & $18.74 \pm 3.27$ & $16.88 \pm 3.67$ & 0.08 & \\
\hline \multirow{4}{*}{ Physical Activity } & Before the intervention & $2.28 \pm 1.02$ & $2.33 \pm 1.04$ & 0.84 & \multirow{4}{*}{$\begin{array}{l}\text { The Mann- } \\
\text { Whitney }\end{array}$} \\
\hline & One month after the intervention & $2.64 \pm 1.05$ & $2.33 \pm 1.00$ & 0.12 & \\
\hline & Two months after the intervention & $2.83 \pm 0.90$ & $2.31 \pm 0.89$ & 0.05 & \\
\hline & Three months after the intervention & $2.87 \pm 0.90$ & $2.44 \pm 0.82$ & 0.01 & \\
\hline \multirow{4}{*}{ Correct habits } & Before the intervention & $2.43 \pm 1.02$ & $2.35 \pm 1.008$ & 0.67 & \multirow{4}{*}{$\begin{array}{l}\text { The Mann- } \\
\text { Whitney }\end{array}$} \\
\hline & One month after the intervention & $2.70 \pm 0.93$ & $2.35 \pm 0.92$ & 0.05 & \\
\hline & Two months after the intervention & $2.87 \pm 0.83$ & $2.46 \pm 0.77$ & 0.006 & \\
\hline & Three months after the intervention & $2.91 \pm 0.81$ & $2.52 \pm 0.75$ & 0.015 & \\
\hline \multirow{4}{*}{ Total } & Before the intervention & $24.13 \pm 3.54$ & $23.69 \pm 4.64$ & 0.59 & \multirow{4}{*}{$\begin{array}{l}\text { Indepen- } \\
\text { dent t-test }\end{array}$} \\
\hline & One month after the intervention & $26.43 \pm 3.11$ & $24.13 \pm 3.99$ & 0.001 & \\
\hline & Two months after the intervention & $26.72 \pm 3.68$ & $24.10 \pm 3.99$ & 0.001 & \\
\hline & Three months after the intervention & $27.62 \pm 3.50$ & $24.23 \pm 3.96$ & $<0.001$ & \\
\hline
\end{tabular}

URA

The findings demonstrated no significant difference between the experimental and control groups before the intervention concerning the mean score of lifestyle dimensions. However, there was a significant difference between the two groups after the intervention in terms of interpersonal relationships, stress management, exercise, physical activity, and nutrition (post-test) $(\mathrm{P}<0.001)$ in a way that the mean scores in the experimental group were higher than the control group. In general, the two groups were similar in terms of lifestyle mean scores before the intervention. However, the two groups differed significantly after the intervention, and the lifestyle improved in the experimental group (Table 3 ).
The results showed no significant difference between the experimental and control groups before the intervention regarding the mean score of obesity control performance. However, significant differences were observed between groups after the intervention (post-test) concerning all dimensions, including diagnosis and follow-up, nutritional performance, physical activity, and correct habits $(\mathrm{P}<0.001)$, and the experimental group obtained higher scores. In other words, the intervention made two groups differed significantly considering obesity performance and improved this performance in the experimental group (Table 4). 


\section{Discussion}

The continuous care model can result in care acceptance, comprehension enhancement, and appropriate performance through designing and developing programs. Consequently, it can be beneficial in controlling obesity and its possible complications [17]. The results indicated that interventions, such as education, care, and counseling, are effective in weight control performance. This model emphasized all factors affecting lifestyle (comprehension development, responsiveness, exercise, nutrition, stress management, and interpersonal relationships), focused on the susceptibility process, and caused person engagement in self-care. The intervention significantly increased the total score of lifestyle and its dimensions, i.e., interpersonal relationships, stress management, exercise, physical activity, and nutrition in the experimental group, leading to participants' lifestyle promotion.

Rahimi et al.'s results were in line with our results [20]. Similarly, Sadeghi Sherme et al. showed that implementing the continuous care model improves the quality of life in patients who underwent coronary artery bypass graft [23]. Anjomanian indicated merely a statistically significant difference between two groups concerning interpersonal relationships using a continuous care model that is consistent with the results of this study [18]. In this care model, attention is paid to planning for physical activity and physical mobility. This is one of the reasons for the weight adjustment resulting from implementing the physical mobility program. People with high BMI suffer from obesity and being overweight because of impulsivity [24]. Consistent with other studies, the present research unraveled the significant role of intervention in improving nutritional performance and enhancing correct habits, physical activity, and obesity control performance. This intervention can be considered an essential factor in reducing complications and improving symptoms of health problems along with other treatments [20, 25 ]. Investigating the effect of the continuous care model on blood pressure and weight control in hemodialysis patients, Rahimi demonstrated that a proper exercise program could be effective in terms of weight loss [20].

In the same way, the study above showed that by improving physical activity, abandoning incorrect lifestyle habits, and enhancing lifestyle, overweight individuals could reduce their weight and benefit from its positive consequences, including improvements in blood sugar, lipids, and blood pressure control [26]. In addition, the current study results showed that the continuous care model had no significant effect on BMI that is in line with Rahimi et al., revealing no significant role for this model concerning BMI in hemodialysis patients [20]. However, the findings were not consistent with those reported by Ely et al., Alizadeh et al., and Ghavami et al., which can be due to inadequate supervision for these activities implementation in the present study $[17,26,27]$

\section{Conclusion}

This study showed that the implementation of a continuous care model using a continuous approach could be an effective and applicable nursing intervention for improving the lifestyle of obese people. Implementing this model can benefit from controlling obesity since there is effective communication between the patient and the nurse. Therefore, this care model is suggested along with other usual care methods for obese middle-aged people. Sufficient evidence shows that implementing a continuous care model can significantly affect various lifestyle domains in obese patients. Concerning limitations, this research suffered from its cross-sectional design and the instruments for data collection, namely, questionnaire and self-question methods, since participants could refrain frain from providing honest responses. Moreover, the large number of questions prolonged the duration of completing the questionnaire, which could reduce the accuracy of the answers. Besides, this study was carried out on middle-aged people, so the findings cannot be generalized to other age groups.

\section{Ethical Considerations}

\section{Compliance with ethical guidelines}

This study was approved by the Ethics Committee of the Gonabad University of Medical Sciences (Code: IR.GMU.REC.1394.3).

\section{Funding}

This research did not receive any grant from funding agencies in the public, commercial, or non-profit sectors.

\section{Authors' contributions}

Study design: Mitra Tavakolizadeh, Mahdi Moshki, and Ali Delshad; Manuscript preparation and data collection: Mitra Tavakolizadeh; Statistical analysis: Mahdi Basiri Moghadam; Manuscript review: All authors. 


\section{Conflict of interest}

The authors declared no conflict of interest.

\section{Acknowledgments}

The authors would like to acknowledge and thank the Clinical Research Development Unit at Gonabad University of Medical Sciences for their contribution to this research article.

\section{References}

[1] McGee M. From makeover media to remaking culture: Four directions for the critical study of self-help culture. Sociology Compass. 2012; 6(9):685-93. [DOI:10.1111/j.1751-9020.2012.00485.x]

[2] Biro FM, Wien M. Childhood obesity and adult morbidities. The American Journal of Clinical Nutrition. 2010; 91(5):1499S-1505S. [DOI:10.3945/ajcn.2010.28701B][PMID] [PMCID]

[3] Nam GE, Kim YH, Han K, Jung JH, Rhee EJ, Lee SS, et al. Korean society for the study of obesity. Obesity fact sheet in Korea, 2019: Prevalence of obesity and abdominal obesity from 2009 to 2018 and social factors. Journal of Obesity \& Metabolic Syndrome. 2020; 29(2):124-32. [DOI:10.7570/jomes20058][PMID] [PMCID]

[4] van Ginneken V, Sitnyakowsky L, Jeffery JE. “Infectobesity: Viral infections (especially with human adenovirus-36: Ad-36) may be a cause of obesity. Medical Hypotheses. 2009; 72(4):383-8 [DOI:10.1016/j.mehy.2008.11.034][PMID]

[5] Jeffcoat R. Obesity - a perspective based on the biochemical interrelationship of lipids and carbohydrates. Medical Hypotheses. 2007; 68(5):1159-71. [DOI:10.1016/j.mehy.2006.06.009] [PMID]

[6] Babaniamansour S, Aliniagerdroudbari E, Niroomand M. [Glycemic control and associated factors among Iranian population with type 2 diabetes mellitus: Across-sectional study (Persian)]. Journal of Diabetes \& Metabolic Disorders. 2020; 19(2):933-40. [DOI:10.1007/s40200-020-00583-4][PMID][PMCID]

[7] Niroomand M, Babaniamansour S, Aliniagerdroudbari E, Golshaian A, Meibodi AM, Absalan A. [Distress and depression among patients with diabetes mellitus: Prevalence and associated factors: A cross-sectional study (Persian)]. Journal of Diabetes \& Metabolic Disorders. 2021; 20(1):141-51. [DOI:10.1007/s40200020-00721-y][PMID] [PMCID]

[8] Zare N, Keshavarzi S, Zeighami B. [Some risk factors of obesity in rural women of Zarrindasht: Using linear regression odds ratio (Persian)]. Zahedan Journal Research in Medical Sciences. 2017; 19(2):e94807. https://sites.kowsarpub.com/zjrms/articles/94807.html

[9] Babaniamansour P, Mohammadi M, Babaniamansour S, Aliniagerdroudbari $\mathrm{E}$. [The relation between atherosclerosis plaque composition and plaque rupture (Persian)]. Journal of Medical Signals and Sensors. 2020; 10(4):267-73. [DOI:10.4103/jmss. JMSS_48_19][ PMID] [PMCID]

[10] Wilsgaard T, Jacobsen BK, Arnesen E. Determining lifestyle correlates of body mass index using multilevel analyses: The tromsø study, 1979-2001. American Journal of Epidemiology. 2005; 162(12):1179-88. [DOI:10.1093/aje/kwi328] [PMID]
[11] Rock CL, Flatt SW, Barkai HS, Pakiz B, Heath DD. Walnut consumption in a weight reduction intervention: Effects on body weight, biological measures, blood pressure and satiety. Nutrition Journal. 2017; 16(1):76. [DOI:10.1186/s12937-017-0304-z] [PMID] [PMCID]

[12] World Health Organization. Achieving quality health services for all, through better water, sanitation and hygiene. Switzerland: World Health Organization; 2020. https://apps.who.int/ iris/bitstream/handle///9789240009493-eng.pdf

[13] Hinkle JL, Cheever KH. Brunner \& suddarth's textbook of medical-surgical nursing. 14th edition. India: Wolters Kluwer India Pvt Ltd; 2018. https://jelaser.dk/sites/default/files/webform/pdf-brunner--textbook-of-medical-sur.pdf

[14] Farahmand S, Abdolhoseini A, Aliniagerdroudbari E, Babaniamansour S, Baratloo A, Bagheri-Hariri S. [Point-of-care ultrasound modalities in terms of diagnosing acute decompensated heart failure in emergency department; A diagnostic accuracy study (Persian)]. Internal and Emergency Medicine. 2020; 15(3):491-9. [DOI:10.1007/s11739-019-02233-x] [PMID]

[15] Habib SH, Saha S. Burden of non-communicable disease: Global overview. Diabetes and metabolic syndrome: Clinical Research and Reviews. 2010; 4(1):41-7. [DOI:10.1016/j. dsx.2008.04.005]

[16] Salyer J, Flattery MP, Joyner PL, Elswick RK. Lifestyle and quality of life in long-term cardiac transplant recipients. Journal of Heart and Lung Transplantation. 2003; 22(3):309-21. [DOI:10.1016/s1053-2498(02)00552-1][PMID]

[17] Ghavami H, Ahmadi F, Entezami H, Meamarian R. [The effect of continuous care model on diabetic patients' blood pressure (Persian)]. Iranian Journal of Medical Education. 2006; 6(2):87-95. http://ijme.mui.ac.ir/article-1-219-en.html

[18] Khankeh H, Anjomanian V, Ahmadi Fallahi Khoshknab M, Rahgzar M, Ranjbar M. [Evaluating the effectiveness of continuous care model on quality of life in discharged schizophrenic patients from Sina educational and medical center, Hamedan, 2007 (Persian)] . Iranian Journal of Nursing Research. 2010; 4(15):60-70. http://ijnr.ir/article-1-170-en.html

[19] Mohammadi Zeidi I, Pakpour Hajiagha A, Mohammadi Zeidi B. [Reliability and validity of Persian version of the health-promoting lifestyle profile (Persian)]. Journal of Mazandaran University Medical Sciences. 2012; 21(1):102-13. http://jmums.mazums.ac.ir/article-1-955-en.html

[20] Rahimi A, Ahmadi F, Gholyaf M. [Effects of applying continuous care model on quality of life in hemodialysis patients (Persian)]. Razi Journal of Medical Sciences. 2006; 13(52):123-34. http://rjms.iums.ac.ir/article-1-622-en.html

[21] BagheriHariri S, Bahreini M, Farshidmehr P, Barazandeh S, Babaniamansour S, Aliniagerdroudbari E, et al. [The effect of extended-focused assessment with sonography in trauma results on clinical judgment accuracy of the physicians managing patients with blunt thoracoabdominal trauma (Persian)] Archives of Trauma Research. 2019; 8(4):207-13. http:// archtrauma.kaums.ac.ir/article_119118.html

[22] Molazem Z, Rezaei S, Mohebbi Z, Ostovan MA, Keshavarzi S. [Effect of continuous care model on lifestyle of patients with myocardial infarction (Persian)]. ARYA Atheroscler. 2013; 9(3):186-91. [PMID] [PMCID]

[23] Sadeghi Sherme M, Razmjooei N, Ebadi A, Najafi Mehri S, Asadi Lari M, Bozorgzad P. [Effect of applying continuous care 
model on quality of life of patients after coronary artery bypass graft (Persian)]. Iranian Journal of Critical Care Nursing. 2009; 2(1):1-6. http://jccnursing.com/article-1-109-en.html

[24] Gillis LJ, Kennedy LC, Gillis AM, Bar-Or O. Relationship between juvenile obesity, dietary energy and fat intake and physical activity. Journal of the International Association for the Study of Obesity. 2002; 26(4):458-63. [DOI:10.1038/ sj.ijo.0801967][PMID]

[25] Tovar A, Must A, Metayer N, Gute DM, Pirie A, Hyatt RR, et al. Immigrating to the US: What Brazilian, Latin American and Haitian women have to say about changes to their lifestyle that may be associated with obesity. Journal of Immigrant and Minority Health. 2013; 15(2):357-64. [DOI:10.1007/ s10903-012-9665-8][PMID] [PMCID]

[26] Ely AC, Befort CA, Duncan AB, He J, Gibson C, Sullivan $\mathrm{DK}$, et al. A chronic care model program incorporating group office visits for obesity treatment in primary care. Kansas Journal of Medicine. 2011; 4(4):87-98. [DOI:10.17161/kjm. v4i4.11391]

[27] Alizadeh Z, Younespour S, Mansrnia MA. [Long term effects of a continuous and intermittent aerobic exercise on weight changes and body fat percentage in overweight and obese women (Persian)]. Tehran University Medical Journal. 2013; 70(10):630-9. http:/ / tumj.tums.ac.ir/article-1-66-en.html 